\title{
More funding needed to wipe out rinderpest
}

\section{Sally Goodman}

While Britain and Uruguay continue to battle against foot-and-mouth disease, another devastating livestock disease, rinderpest, could be on the point of total eradication. It would be only the second disease in history, after smallpox, to have been wiped out.

But researchers warn that if funding for the final stages of the eradication programme remain unsecured, the efforts so far made to eliminate the disease will be wasted.

Rinderpest is a debilitating and often fatal viral disease that primarily affects cattle, buffaloes, yaks and wild ungulates. It has had catastrophic effects on agriculture in Africa and Asia in the recent past. But an extended vaccination and international control programme has confined the disease to a few isolated reservoirs in Pakistan and the wartorn areas of Somalia and southern Sudan, where control has been more difficult.

According to Peter Roeder of the Global Rinderpest Eradication Programme, which is coordinated by the UN Food and Agriculture Organization, the world has never been this close to the eradication of rinderpest. "But there is a real danger of complacency setting in," he says, "and a real risk of epidemic or even pandemic recurrence if control efforts falter."

Where it still exists, rinderpest occurs in a mild form and could persist unnoticed should it reach Europe or the United States through international livestock trade.

Roeder estimates that a further US\$15 million are needed to fund a final eradication effort over the next five years. This should focus on disclosing and eliminating any remaining reservoirs of the virus once vaccination has ceased, he says, and absence of disease should be verified through serological surveillance. He also recommends that a global emergency programme be put in place to deal quickly with any resurgence.

Most research into rinderpest is funded by the European Union through the PanAfrican Programme for the Control of Epizootics, which will end in 2004. The UK Department for International Development and the USAID programme also support fieldwork in Somalia and Sudan. Laboratory research is mainly focused on new-generation vaccines, which could be used to 'ringfence' vaccination, and on the development of more sensitive and specific diagnostic kits to differentiate between rinderpest and another closely related disease, peste des petits ruminants.

The Pirbright laboratory of the Institute of Animal Health (IAH) in Surrey, UK, houses the World Reference Laboratory for rinderpest. Staffed by only three people, it has recently developed a diagnostic kit that uses the same 'dipstick' technology used in

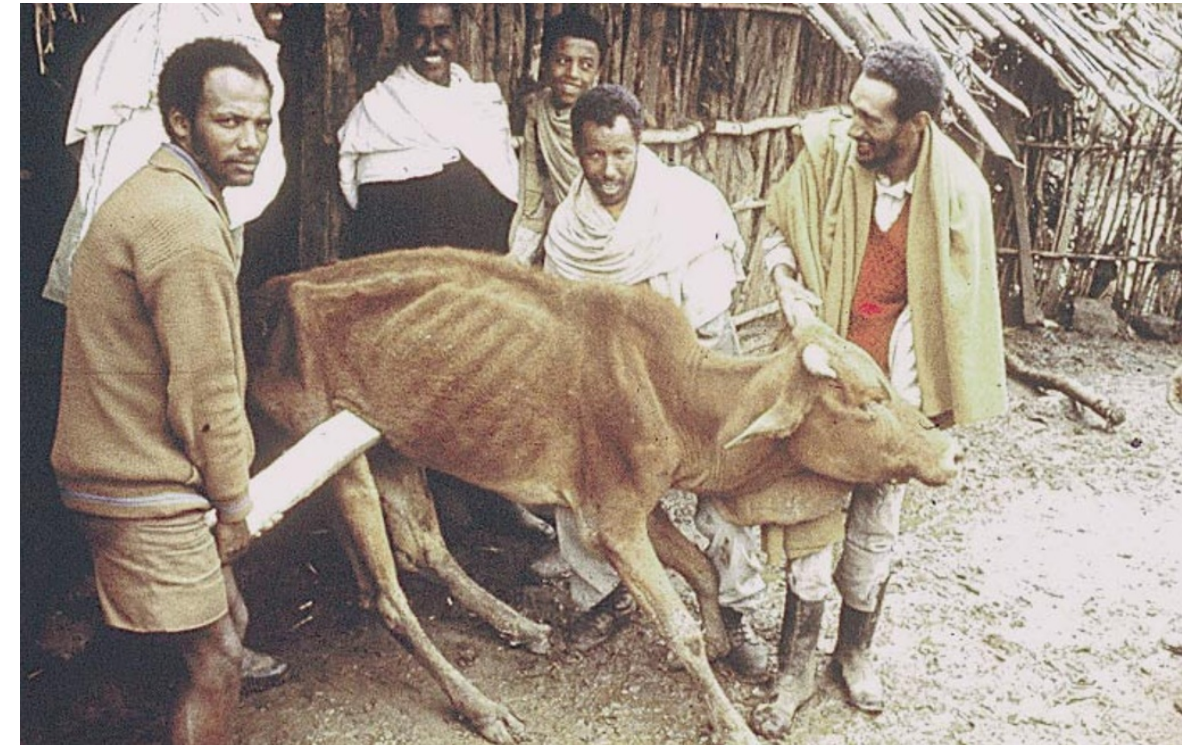

On its last legs: the livestock disease rinderpest could soon be eradicated if funding is maintained.

home pregnancy tests. The kit, which gives results within 10 minutes, is already being used in Pakistan. John Anderson, who heads the development team, says that such tests will be vital in the final surveillance stage of the eradication process.

The IAH is also developing marker vaccines that will differentiate between infected and vaccinated cattle. And a national agriculture laboratory in Montpellier, France, has begun work to develop an oral vaccine in pellet form.
But funding is most urgently needed to develop capacity to fight the disease in the field. Affected countries must have adequate local resources and expertise to take part in the final stages of the eradication programme, says Manzoor Hussain, an animal health officer in Pakistan. "The main problem is that we lack efficient reporting systems," he says.

Meanwhile, Anderson has had to stop his own work on rinderpest to concentrate on foot-and-mouth testing in Britain.

\section{Plans for GM livestock fail the poor}

\section{David Adam, London}

Research to develop genetically modified (GM) animals is focusing on producing cheaper food for the West, and risks ignoring the technology's potential to help agriculture in the developing world, the Royal Society warned this week.

A report on the use of GM animals calls for greater investment for work to create animals resistant to foot-and-mouth disease and sleeping sickness. "Creating diseaseresistant animals is especially important for the farmers in the developing world and the society recommends that research efforts on this technology are addressed with particular urgency," the report says.

It calls for greater cooperation between universities and biotechnology companies to develop disease-resistant GM animal technology and for "a willingness to share knowledge currently restricted under patent and licensing agreements".

Bob May, the society's president, says big agricultural businesses have little incentive to address problems unique to countries that cannot afford GM technology. The recommendation "must be taken seriously because GM technologies could have great benefits for developing countries," he says.

The report also recommends a ban on rearing GM fish in marine pens. Approval for commercial production of GM salmon should only be given if the fish are kept in landlocked tanks, it states. This echoes recommendations made by a panel from the Royal Society of Canada earlier this year (see Nature 409, 749; 2001). A US company, Aqua Bounty Farms, has developed GM salmon that grow faster than normal, prompting fears that the fish will disrupt natural salmon populations if they escape (see Nature 406, 10-12; 2000).

All laboratories working on GM animal technology should have emergency plans for containment, the report adds, in case the animals escape or are released deliberately. 